\title{
Study on the Training Mode of Talents in "Artificial Intelligence and Law"
}

\author{
Teng $\mathrm{Hu}^{1, *}$
}

\author{
${ }^{1}$ School of Public Affairs and Administration, University of Electronic Science and Technology of China, Chengdu, \\ Sichuan 611730, China \\ *Corresponding author. Email: ssorde@163.com
}

\begin{abstract}
The development of artificial intelligence technology, which has caught more public attention, is of great significance in determining future talent training and career prospects. Given the current situation, the paper analyzes the deficiencies in legal education in the context of artificial intelligence, and probes into the framework of talent training, trying to propose and explain development approaches of law education in response to artificial intelligence.
\end{abstract}

\section{Keywords: "artificial intelligence and law", law education, talent training, thinking}

\section{INTRODUCTION}

Since its birth in the University of Bologna in Italy in the 11th century, legal education has been evolving and integrating. Great leap has been made over the past thousand years. The law industry has been relatively immune to previous industrial and scientific and technological revolutions due to its nature. The operation of legal profession system still follows premodern mode ranging from training of lawyers to the selection of judges, which is true of both civil law system and common law system. In short, legal education is relatively old-fashioned. Despite the everchanging technology, no fundamental change has been made in the logic of legal profession. Emerging technologies have long been employed mainly in noncore areas, such as improving efficiency through digital office and management systems. Technology contributes little to substantive legal solutions, such as litigation plans and the formation of judgement, let alone replacing legal practitioners.

However, artificial intelligence (AI) technology may make a difference. As a technology that attempts to understand the essence of human intelligence and to simulate and extend human intelligence, artificial intelligence can, in theory, efficiently complete information pooling, regulatory consolidation and execution, or imitate legal reasoning process through the establishment of appropriate calculation model, thus providing solutions and corresponding interpretation in response to legal issues. [1] The rapid development of the technology prompted people, even conservative and proud lawyers, to face up to the challenges posed by AI. In 2015, the US-based Altman Weil company found that $85 \%$ of the surveyed hold that AI technology can replace work involving paralegals and junior counsels in the era of AI. While the results may not necessarily reflect industry trends, the attitudes of legal professionals toward AI can be seen. Against such background, the Development Plan for New Generation of Artificial Intelligence issued by the State Council in 2017 proposed the integration of law education and artificial intelligence, creating a new training mode of "artificial intelligence plus law". In April 2018, Innovative Action Plan for Artificial Intelligence in Colleges and Universities mentioned the AI talent training: its focus lies on perfect the training target, rationally arrange disciplines and strengthen personnel training. At the National Education Conference, General Secretary Xi Jinping proposed to "promote collaborative innovation of industry-university-research, actively participate in the implementation of innovation-driven development strategy, and focus on cultivating innovative, compound and applied talents". [2] To fully implement the spirit of General Secretary Xi's speech, law education should double their efforts to transform experimental law to intelligent law, and respond to the challenges posed by new technologies such as Internet, big data and AI to the legal system with a broadened horizon and a new look.

\section{IMPACT: THE ADVENT OF THE ERA OF ARTIFICIAL INTELLIGENCE LAW}

Judge Posner of the United States once described the legal industry in this way: "a cartel of service providers involving the law of society", which means a monopolized industry. Such statement vividly reveals that given its attributes, legal industry is immune to industrial and technological revolutions. Operation of the legal profession system, including the cultivation of lawyers and the selection of judges, is no different from pre-modern counterparts. The West has proved it too. 
Therefore, the traditional legal education itself is still on the beaten path, with no substantial changes since it falls into a pattern in modern times.

However, experts hold that thanks to artificial intelligence, "online legal services, robot legal services and other alternative business models can provide legal services to end users at a lower price, which is expected to make legal services standardized, commoditized, automated and democratized. Commoditization indicates that legal services is no longer exclusive to specific human lawyers, but can be delivered in an automated manner. Democratization means that most people are entitled the access to legal services at a lower cost." [3] As a result, traditional legal education seems to be under attack, forcing legal educators to face up to the impact of artificial intelligence on legal education.

In fact, internationally, such thinking and even action emerged much earlier than expected. For example, the first Artificial Intelligence Plus Law Conference was held at Boston University in 1987, and the IAAIL (International Association for Artificial Intelligence and Law) was founded. [4] Many wellknown law schools outside China have already initiated in setting of law courses. In 1984, Professor Paul Brist of Stanford University Law School and others gathered to discuss whether "artificial intelligence and law" should be offered. Harvard Law School is fast in action. "Artificial intelligence and law" seminars have been available since 1985 . The courses currently offered include: "Frontiers of Cyber Law: Artificial intelligence, Automation and Information Security", "Legal Advice and Strategy in the Data Age", "Comparative Data Privacy", "Compliance and Computing", etc. Other universities are close at its heels. Since 2012, Georgetown University has offered courses in Robotics Law, Science and Technology Law and Policy, Computer Programming for Lawyers, and Electronic Legal Investigation. In 2015, Melbourne Law School began offering courses on the development of legal applications.

However, China is a late comer as for probe into the influence of AI technology on law, with few integration of AI and law or big data. Development Plan for New Generation of Artificial Intelligence issued by the State Council first proposed the combination of legal education and artificial intelligence, creating a new mode integrating the two. Thanks to such policies and government support, the development of AI and law has been in the ascendant in 2017: the number of academic papers involved increased sharply, and some pioneers attempted to combine artificial intelligence with legal education. It is worth mentioning that in 2018, Tsinghua University set up the interdisciplinary law education program "Full-time Master of Law of Computational Jurisprudence", and offered a series of technical courses combining Internet, big data and artificial intelligence. Law and Big Data Research Center of Tsinghua University School of Law can be utilized for studies on the application of big data, artificial intelligence and other new technologies in the legal industry, in a bid to build an integrated industryuniversity-research-application system in the field of legal big data and artificial intelligence. The Law School of Renmin University of China also carried out reforms in law plus science and technology teaching by offering a series of interdisciplinary courses. For example, in the course of "Internet Finance", experts in new technology are invited to impart the application of AI technology in big data credit investigation, the basic principle of block chain and its application in finance. In addition, the course "Introduction to Big Data Analysis" is also offered. In 2018, Southwest University of Political Science \& Law set up School of Artificial Intelligence and Law, offering graduate courses such as "Legal Retrieval Technology" and "Mining, Analysis and Application of Big Legal Data". Meanwhile, it also formally trained master and doctoral students in "artificial intelligence and law". It's no overstatement to say that the past two years constitute the most glorious chapter in "artificial intelligence and law" in China.

\section{REFLECTION: PROBLEMS EXISTING IN LEGAL EDUCATION AGAINST THE BACKGROUND OF ARTIFICIAL INTELLIGENCE}

However, despite the great progress in AI and law both in China and abroad in recent years, it obtained more buzz than real achievement. It can be largely explained by the failure to transform traditional law education, which cripples talent training of "artificial intelligence and law". A typical example is that Brian Z Tamanaha, a professor at Washington University Law School in St. Louis, US, attacks the "4+3" (4-year undergraduate plus 3-year law school education) legal education model in the US in his book Failing Law School, holding that three years of law school is not necessary, two years at the most, maybe one year. [5] However, the traditional law education in China is a four-year undergraduate law education directly after entering the university, which makes it difficult to adapt to the future law practice led by robots and artificial intelligence. Lawyers of the future will do totally different routines than lawyers of today, so different education is required. Although such statement is not conclusive, it proves the AI and law in traditional law training mode is in deep water.

However, the essential question is not the formal one, like years of training, but the need to reconstruct and set up knowledge. The growth of AI and law depends not only on data and specific algorithms involving law, but also on interdisciplinary talents with 
know-how on both technology and law. The reality in China indicates that talent cultivation and reserve of AI and law fail to guarantee human resources support. What's worse, lack of talents will take a toll on the development of AI and law. Such shortage can be explained by issues in the fields of law education and artificial intelligence technology.

\section{A. Traditional law education enjoys inadequate} knowledge of artificial intelligence technology

1) Data statistics and analysis techniques have not been applied in traditional law education and research: Students majoring in law nurtured under traditional liberal arts training mode are prone to view legal issues from a qualitative rather than a quantitative perspective. The rise of empirical research in recent years still fails to boost quantitative research. The few existing empirical studies still mostly employ descriptive statistical methods, that is, to explain the external world simply through percentage, growth rate and graph, rather than deduction statistical methods such as correlation, regression and clustering. An important and practical reason for such situation lies on that researchers lack knowledge about techniques of data statistics and analysis, let alone skillfully utilization. Such weakness will be highlighted in the age of big data. Given that traditional law experts are not proficient in big data, they need helping hands from data experts within Baidu, Tencent, Alibaba and other companies to obtain the targeted evidence when faced with massive data.

2) Law educators are unfamiliar with big data algorithms: In the era of "small data", the application of statistical "algorithms", or legal empirical research, is enough for work. However, the massive, huge data flow has obsoleted such "algorithm", as it fails to accurately grasp the legal phenomenon and the law of judicial operation. More sophisticated and technical algorithms are urgently required. However, legal practitioners are not professional, most of them aren't equipped with knowhow on the application of algorithms to deal with big legal data, let alone the establishemnet of a successful algorithm model. Examples of large-scale use of algorithms to build judgment patterns are zero.

3) Traditional law majors fail to take an objective view of artificial intelligence: The mushroom growth of artificial intelligence has caught the attention of more legal personnel, who are diligent in learning and studying relevant knowledge and technology. However, objective cognition of $\mathrm{AI}$ and law is still not established. Some legal personnel don't even care about artificial intelligence. When talking with experts in artificial intelligence, they may equate the predictions made by artificial intelligence with human reasoning, or hold that artificial intelligence will completely overturn human society and human beings will become the slaves of robots. Such fantasies are often ridiculed, leaving AI experts shocked and discouraged from further dialogue.

\section{B. Artificial intelligence technology itself fails to integrate with law industry}

1) Artificial intelligence technicians lack necessary law knowledge: Many programmers, though highly skilled at coding, cannot understand the product requirements of law personnel, which is a field they never set feet in. This leads to products with limited actual role and no desired effect. It's hard to escape hyperventilation about AI and law in these days, however, talents who really understand and master AI technology and machine learning algorithm is few, some of which even never forayed into the field before.

2) Insufficient investment from artificial intelligence in law and artificial intelligence: Despite the importance many law and technology companies attach on AI and law, and their considerable investments, such efforts are not on a par with what other fields invest in AI. This is a far cry from Google's DeepMind's investment in the development of alphago artificial intelligence, or the efforts made by Baidu, Tencent, Alibaba and other companies in developing general artificial intelligence products. In reality, Chinese companies keen on research and application of AI and law are far smaller in size, talent and capital than big technology companies. Even if a big tech company, such as Iflytek Co.Ltd, steps in, its core technology remains popular-type voice rather than lawspecific AI. However, such voice technology has not been widely employed in current trial practice, as the failure of transform popular-type voice to law-specific voice resulting from inadequate manpower and resources investment. In particular, the situational issue of multiple interactions and arguments in complex court trials have not been solved, and the last-mile of technical obstacles to the real practical use of legal voice have not been overcomed.

3) The use of artificial intelligence in technology is too utilitarian: Artificial intelligence technology is now mainly adopted in finance, automobile, Internet and other fields with high income and high salary, which is true of countries outside China. In December 2017, Bloomberg reported that artificial intelligence would occupy 99 percent of investment institutions on Wall Street. [6] In the auto industry, Tesla has recruited a lot of AI talent. Many AI talents graduated from colleges and universities are attracted by the high salaries of 
Internet companies such as BAT and devote themselves to them. Compared with these high-paid industries, the legal profession is less attractive, making it difficult to reach highly skilled people, which may last for a long time.

In short, the shortage of talents has become the biggest practical factor that holds back the growth and application of AI and law. After all, as the saying goes, One can't make brick without straw. One also can't perform well in "artificial intelligence" without qualified talents. In particular, when machine learners are asked to classify new data, classification design inevitably introduces some inductive bias, that is, machine learners will have inevitable bias in "cleaning" data, designing and verifying hypothesis. In terms of this crucial point, the legal community seems illprepared to invest fully in "AI and law", and neither is the AI community, particularly the tech industry. Perhaps only when legal practitioners and technical talents put themselves in each other's shoes, fully understand each other's needs and expectations, and solve the practical problems in the application of law and technology, can artificial intelligence be integrated with the law field.

\section{SOLUTION: TO BUILD THE TALENT TRAINING FRAMEWORK OF COMPOUND "ARTIFICIAL INTELLIGENCE AND LAW"}

As talent occupies the dominant position in artificial intelligence, the cultivation of qualified interdisciplinary talents is the first and foremost issue. Law education, the main shaper and founder of legal theory, is required to master the forefront theory in response to artificial intelligence and serve as the theoretical cornerstone. The foregoing indicates that universities inside and outside China are exploring the subject and course system of "artificial intelligence and law". However, such exploration is still in the stage of fumbling, and no complete system is established. As a result, what is needed now is to sort out the basic framework of cultivating legal talents adapting to the era of artificial intelligence. The author holds that such framework falls into the following three camps.

\section{A. Clarifying the issue of talent entry and exit}

The issue of "entry" and "exit" deserves mention among any higher education in China. The "entry" refers to the target and scale of enrollment, while "exit" the employment of talents cultivated. In the field of artificial intelligence, a question worth thinking is: should the perspective students of law education change accordingly? Take "entry" as an example. Currently, all Chinese institutions of higher learning enroll undergraduate law students from liberal arts majors. However, when it comes to artificial intelligence, the lack of or indifference to science knowledge will inevitably undermine the absorption of relevant knowledge and talent cultivation to a certain extent. Given the basic knowledge of algorithm can not be mastered, commanding the crossover knowledge of "artificial intelligence and law" is obvious a fruitless approach. The oncoming reform of the college entrance examination in science and arts (cancel the division of students into different tracks in high school), as well as the attention to the combination of majors in postgraduate admission, can alleviate the entry issue to some extent. The issue of "exit" seems trickier. The impact of traditional mindset is huge. The exit of law undergraduate major has been affected by many factors, and even has been listed in majors with unpromising employment for several years. [7] The logic of the reality is twofold: too many law graduates, and limited job options including judicial units, in-house lawyer and law office. The further integration of "artificial intelligence and law" will promote the diversification of training of law major in colleges and universities, some of which may even be phased out in this process. While doing so, some new "exit" for law students will be found, such as the development and integration of relevant legal software. Therefore, clarifying the "entry and exit" of legal education in the context of artificial intelligence matters not only the cultivation of talents, but also the development of law schools.

\section{B. Speeding up the cultivation of interdisciplinary talents}

The booming of artificial intelligence will lead to a reallocation of professional personnel. The orientation of future legal professionals is likely to be reviewers or value judges. It may be easier and more convenient to train law-savvy technicians than to train tech-savvy lawyers. Considering the reality, the training of "techsavvy legal personnel" is the main approach of law training at present. Therefore, interdisciplinary is the basic requirement to be met. Besides the ability of value judgment and legal thinking, attention should also be paid to the ability of applying artificial intelligence to legal activities. According to Development Plan for New Generation of Artificial Intelligence, the creation of compound legal talents requires universities to integrate artificial intelligence education in the original basic classroom. The integration of "artificial intelligence and law" will inevitably involve ethics, computer science, sociology and other disciplines, so it is necessary to establish an interdisciplinary platform. The corresponding supporting curriculum system also should be implemented. The retrieval of big legal data, the analysis and discussion of typical examples of artificial intelligence, the relationship between artificial intelligence and ethics and legal theory and other relatively easy teaching courses should be offered. In addition, the practice and teaching of artificial intelligence should be strengthened. Colleges and 
universities can cooperate with enterprises and law offices inside and outside China, allowing students internship platforms, the access to artificial intelligence robots and artificial intelligence operating systems, thus accelerating the transformation of theoretical results into practical results.

\section{Strengthening cross-disciplinary research}

The current development of artificial intelligence indicates that slim chance are the academic field being replaced by robots. It is hard to imagine a roboticist, technically or ethically. However, not being replaced does not mean not being hit. Especially in the teaching of "artificial intelligence and law", necessary knowledge reserve has become the key node to impart relevant knowledge to students. Now, the first and foremost to be solved is how to build the subject system and curriculum system of "artificial intelligence and law", and How to compile its teaching materials. In the long run, teachers will face the challenge of artificial intelligence, and even every professional course will face issues imposed by AI (perhaps courses on history of law will be spared). It is a must for most legal educators to renew their knowledge reserve and strengthen the research of interdisciplinary subjects.

\section{CONCLUSION}

Despite the reluctance of legal educators to adapt and give up their professional pride, artificial intelligence technology's huge impact on traditional legal education model is true. As Viktor says, "legal big data prejudges legal issues, obtains products and services of great value, or comes up with new cognition, profound views and propositions through the analysis of massive legal data, which is unprecedented." [8] The emergence of "artificial intelligence and law" is destined to revolutionize traditional legal education model. Future legal education and artificial intelligence and other cutting-edge information on science and technology will be increasingly closely integrated. Whether the vision can be realized earlier and faster depends on the reflex arc of legal education. Legal educators are required to adapt to such pace of development and pass it on to students. As the butterfly effect shows, the trivial effort of educators is called for.

\section{References}

[1] Zhao Peng. The Development of Legal Artificial Intelligence Technology and the Response of Legal Education. China Higher Education, 2019.3/4, p.75. (in Chinese)

[2] General Secretary Xi Jinping's important speech leads to new thinking and new actions in education. Chinanews. 2018.9.12. (in Chinese) http://www.chinanews.com/gn/2018/09-12/8625467.shtml

[3] Cao Jianfeng. Ten Trends of Artificial Intelligence + Law. Robot Industry. Issue 5, 2017, p. 86. (in Chinese)
[4] Jiang Ke, The Model of Law Education in Polytechnic Colleges under the Background of Artificial Intelligence Plus [J]. Think Tank Era. 2018, 139(23): 74-77. (in Chinese)

[5] Cao Jianfeng. Prospects and Challenges of Artificial Intelligence Legal Services. Tencent Research Institute, 2017.3.20. (in Chinese)

https://www.tisi.org/4855

[6] Nishant Kumar, How AI Will Invade Every Corner of Wall Street, March 3, 2018,

https://www.bloombergquint.com/business/2017/12/05/how-aiwill-invade-every- corner-of-wall-street

[7] 2019 Employment Report of Chinese College Students, See Where Did All Graduates Go. Sohu Education, August 29, 2019. (in Chinese) https://www.sohu.com/a/337364897_100014885

[8] Yang Tongdan. Legal Big Data is a Revolution in Research Methods. Chinese Social Science, June 2, 2016, second edition. (in Chinese) 